\title{
NICANOR PARRA Y LA GUERRA FRÍA: POESÍA POLÍTICA EN LOS AÑOS CINCUENTA
}

\section{Niall Binns}

La pregunta respecto de si la poesía de Parra es o no política ha hecho correr ríos de tinta. Binns - uno de los más destacados especialistas en Parra en el mundo - la aborda a partir de dos poemas de los años cincuenta, incluidos más tarde en una antología llamada, justamente, Poesía política. Al mirar estos textos con detención se puede tener una idea más nítida del sentido en que la obra de Parra es política.

Rivers of ink have been spent on debating the question of whether Parra's poetry is or is not political. Binns, one of the most wellknown experts on Parra in the world, addresses this matter on the basis of two poems from the 50's, later included in an anthology rightly entitled Poesía Política (Political Poetry). A close look at those texts provides a clear idea that Parra's work is political.

Niall Binns (Londres, 1965). Poeta. Profesor en la Universidad Complutense de Madrid. Estudió en Oxford y Chile y ha publicado los libros de poesía 5 love songs (1999) y Tratado sobre los buitres (2002), y los ensayos Un vals en un montón de escombros: Poesía hispanoamericana entre la modernidad y la postmodernidad (1999), Nicanor Parra (2000), La poesía de Jorge Teillier: la tragedia de los lares (2001), La llamada de España. Escritores extranjeros en la guerra civil (2004), Voluntarios con gafas. Escritores extranjeros en la guerra civil española (2009), entre otros. Con Editorial de la Universidad de Valparaíso, en 2014, publicó Nicanor Parra o el arte de la demolición. Email: nbinns@filol.ucm.es 


\section{BENEDETTI A LA BUSCA DE UN POETA POLÍTICO}

D urante la semana que pasó en Santiago de Chile en octubre de 1969, Mario Benedetti asistió al anuncio de que Nicanor Parra había ganado el Premio Nacional de Literatura y a la proclamación de Pablo Neruda como candidato presidencial del Partido Comunista. Se sorprendió el uruguayo ante algunos comentarios de Neruda en esos días, como señalaría ácidamente en las palabras liminares de "Nicanor Parra o el artefacto con laureles", una entrevista que fue publicada en ese mismo mes de octubre en la revista Marcha y luego, en 1972, en el libro Los poetas comunicantes: "De más está decir que la prensa conservadora destacó con particular fruición la formal promesa del informal candidato: en caso de salir triunfante, respetará la industria privada". "La toma de postura del entrevistador fulguraba en las palabras que seguían a continuación: "En vista de lo cual me fui a La Reina, donde Nicanor vive en su cuarta o quinta soledad, pero sin concederle ventajas a la melancolía"2 (la cursiva es mía).

Ésta y otras "sorpresas" del candidato comunista, autor de Canto general y el poeta político por excelencia de la lengua, significaban para Benedetti una traición de Neruda a su propia herencia. Se había invalidado a sí mismo como poeta político en un momento de alta tensión revolucionaria, tanto en el continente americano como en el resto del mundo. Por supuesto, el uruguayo, como uno de los intelectuales centrales de la Revolución Cubana, sabía que no era el primero en distanciarse de Neruda; conocía perfectamente la carta abierta firmada en 1966 por casi todos los intelectuales de peso residentes en la isla -Alejo Carpentier, Nicolás Guillén, Juan Marinello, Félix Pita Rodríguez, Roberto Fernández Retamar, José Lezama Lima, Virgilio Piñera, Heberto Padilla y un largo etcétera-, en la que habían reprochado a Neruda su presencia en el reciente Congreso del PEN Club de Nueva York, así como el almuerzo que celebró, en su camino de regreso a Chile, con el presidente Fernando Belaúnde Terry en el Perú. La carta concluyó no sólo cuestionándolo, sino pidiendo unas explicaciones que — naturalmente- enfurecerían a Neruda: "Algunos de nosotros compartimos contigo los años hermosos y ásperos de España, otros, aprendimos de

${ }^{1}$ Mario Benedetti, "Nicanor Parra o el artefacto con laureles", en Los poetas comunicantes (Montevideo: Marcha, 1972), 41.

2 Ídem. 
tus páginas cómo la mejor poesía puede servir a las mejores causas. Todos admiramos tu obra grande, orgullo de nuestra América. Necesitamos saberte inequívocamente a nuestro lado en esta larga batalla que no concluirá sino con la liberación definitiva, con lo que nuestro Che Guevara llamó 'la victoria siempre", 3

En esos mismos años de finales de los sesenta, Nicanor Parra —en palabras de Jorge Edwards_ _ "viajaba a Cuba a cada rato y se convertía en el amigo predilecto de Casa de las Américas, en el regalón, para emplear un chilenismo, de Haydée Santamaría y de sus colaboradoras". 4 Seguiría siéndolo — en 1969, Casa de las Américas publicó una antología de Parra, Poemas - hasta la fecha de su inesperada y fatídica tacita de té con la mujer del presidente Nixon, acontecida en Washington D.C. en abril de 1970, en plena guerra de Vietnam, lo que desencadenó un cierre abrupto y violento de las relaciones del antipoeta con la isla.

Seis meses son, sin embargo, muchos meses en la política y también, a veces, en la poesía. En octubre de 1969, Benedetti estaba convencido de haber localizado en La Reina al nuevo poeta político de las Américas, y con ese fin lo perseguiría con sus preguntas a lo largo de la entrevista. "Algún hecho político, ¿ha tenido influencia sobre tu obra?", preguntaba, sin conseguir la respuesta afirmativa que deseaba. Contestaba Parra que esa influencia se habría ejercido no sobre su obra, sino más bien sobre su "persona exterior" o sobre "algunas zonas del alma individual", y citaba al respecto la "Revolución Española", la Segunda Guerra Mundial — "que me hizo vibrar muy profundamente" — y la Revolución Cubana, que fue "la explosión más directa y la que más me ha interesado, la que ha desencadenado más fuerzas". De todos modos, si bien en algún momento quiso escribir un poema sobre la guerra mundial, carecía de los "elementos" necesarios para hacerlo. A fin de cuentas, decía: "Desgraciadamente yo no soy un poeta político; no soy un poeta que trabaja con ideas ni con sentimientos. Yo no sé con qué demonios trabajo". 5

Benedetti no se detuvo ante esta evasiva, insistiendo en que "a veces, a pesar tuyo eres un poeta político, indirectamente político", una idea que Parra aceptó con la condición de que se entendiese "por una especie de reducción al absurdo". De nuevo, subrayaba su distancia res-

${ }^{3}$ Varios autores, "Carta abierta a Pablo Neruda", Casa de las Américas 38 (septiembre-octubre de 1966), 134-135.

${ }^{4}$ Jorge Edwards, Adiós, poeta... (Barcelona: Tusquets, 1990), 144.

${ }^{5}$ Benedetti, "Nicanor Parra", 46. 
pecto de la poesía política, señalando que le interesaba trabajar poéticamente con los "problemas permanentes", más que con lo "transitorio", y más con esas "zonas oscuras del ser" propias de la poesía que con "el dominio de la razón", al que pertenecía la política. Él no era "un poeta de encargo, ni un poeta que trabaje por motivos ideológicos", a pesar de sus posiciones personales - "en la actualidad sufro diariamente con la guerra de Vietnam, con las situaciones africanas y con esa otra guerra lenta que está desmoronando nuestros pueblos, que es la miseria, el subdesarrollo"-, porque se daba cuenta perfectamente de que la poesía política, por muy necesaria que fuese, estaba "condenada a operar con elementos más fungibles" y difícilmente llegaría a concretarse en "obras realmente duraderas". 6

En un momento posterior de la entrevista, Benedetti ensayó un nuevo acercamiento al tema con su mención a "Manifiesto", un poema - aseguraba - que le gustaba mucho y le parecía precursor de "ciertos conflictos en que hoy está inmerso el intelectual, en relación con fenómenos políticos y sociales de distinto orden". Parra respondió largamente, recordando el interés que tenía, en la época de la composición de "Manifiesto" (se publicó como cartel en 1963), por los debates en torno al compromiso político de los surrealistas en los años treinta y por la Revolución China, que él había conocido de cerca en un viaje de finales de los cincuenta, durante el cual quiso enterarse de cuáles serían, según "el código revolucionario chino", los deberes del poeta. Le contestaron así: "Amigo Parra, usted ha estado preguntando insistentemente cuáles son los deberes del poeta revolucionario. Ahora le vamos a contestar. Primero: ubicar al enemigo. Segundo: tomar puntería. Tercero: disparar". Encantado con estos consejos, intentó aplicarlos en Chile al presidente Jorge Alessandri, proyectando un libro titulado Poemas prácticos, que contendría "Manifiesto" y un par de monólogos pronunciados por un personaje que sería el propio Alessandri y que constituirían "una especie de canto del cisne del capitalismo agonizante". Parra fracasó, sin embargo, en su intento: "Ubiqué rápidamente al enemigo, tomé puntería, pero no me atreví a disparar. Realmente, se produjo un proceso de inhibición" y, además, "algo ocurrió después en mi experiencia política personal (no recuerdo exactamente qué) y me desinflé". ${ }^{7}$

\footnotetext{
${ }^{6}$ Benedetti, "Nicanor Parra", 47.

${ }^{7}$ Ibídem, 56.
} 
Hacia el final de la entrevista, hubo un último intento para que Parra se definiera como el poeta político que Benedetti luchaba con tanto empeño por encontrar:

- ¿Cuál crees que es la mejor resonancia, la resonancia más positiva que tiene tu obra en las generaciones más jóvenes, tanto de poetas como de no poetas?

-Una desintegración de la nebulosa cultural añeja, o sea de la nebulosa anterior. En ese sentido, mi trabajo es eminentemente político, y debería operar en un plano muy efectivo. Un antipoema en este sentido no es más que la punta de un alfiler que toca un globo que está por reventar. Se renuncia definitivamente a la escala de valores que nosotros heredamos de nuestros abuelitos. En este sentido es que yo puedo ser considerado como un poeta revolucionario, y con una $\mathrm{R}$ bien grande, y no con $b$ larga sino con una $v$ bien corta, pero muy aguda y penetrante.

-Después de todo, te reconoces un poeta político.

-Poeta político sí, pero no un poeta politiquero.

- De política profunda, entonces.

-¿Qué es la cultura, en último término, sino un proceso político superior? Creo que era Aristóteles quien decía que el hombre era un animal político. La política, concebida en esos términos, evidentemente no puede estar ausente en ninguna obra de creación que se estime. ${ }^{8}$

Parra se reconocía, así, como poeta político y revolucionario en un sentido muy amplio - jugando, por supuesto, con esa $R$ bien grande, con esa $v$ bien corta-, como cuestionador y catalizador, en alguna medida, del desmantelamiento de una sociedad anacrónica, de valores obsoletos. Un poeta político "de política profunda", añadiría Benedetti, con la aprobación de Parra, que conseguía así su deseada reducción al absurdo del concepto, porque si para Aristóteles cada hombre era un animal político, cada obra de creación debía ser, entonces, política también.

\section{POESÍA POLÍTICA EN TIEMPOS DE LA DICTADURA}

En 1983, Nicanor Parra publicó en Santiago la antología Poesía política, editada y prologada por Enrique Lafourcade, pero con una selección y una organización —a juzgar por los numerosos textos inéditos

${ }^{8}$ Ibídem, 60-61. 
y por las secciones nombradas "Cachureo" y "Guatapiques"- que fueran, con casi toda seguridad, obra del propio Parra. El título resultaba tan sorprendente como provocador: sorprendente, porque Parra - a pesar de la insistencia de Benedetti- no solía considerarse un poeta excesivamente politizado, y provocador, porque la "política" de partidos en Chile fue abolida de inmediato después del golpe militar de 1973. Los partidos de la Unidad Popular — con mención específica a "los partidos Comunista o Comunista de Chile, Socialista, Unión Socialista Popular, MAPU, Radical, Izquierda Cristina, Acción Popular Independiente, Partido de la Unidad Popular y todas aquellas entidades, agrupaciones, facciones o movimientos que sustenten la doctrina marxista" - fueron declarados "ilícitos y disueltos" por el Decreto Ley n. ${ }^{\circ} 77$, del 13 de octubre de 1973, y, cuatro días después, el Decreto Ley n. ${ }^{\circ} 78$ declaró "en receso todos los partidos políticos y entidades, agrupaciones, facciones o movimientos de carácter político" no comprendidos en el decreto ley anterior.

Esta prohibición se mantendría vigente hasta la promulgación de la Constitución de 1980, que permitió la organización de algunas agrupaciones de carácter político, pero no fue hasta la puesta en marcha de la Ley Orgánica Constitucional de los Partidos Políticos (marzo de 1987) que se pudo volver a la actividad política con un mínimo de normalidad. ${ }^{9}$

Lafourcade, en su prólogo "Nicanor Parra sin anti-parras", esbozaba vagamente lo que entendía por "político", al decir que "rastreando en [la] obra [de Parra] hemos aislado parte de su poesía política, la que corresponde a su zoon politikon, más poesía que política, pero indistintamente una toma de conciencia real frente a diversas situaciones ocurridas en el mundo y en nuestro país". ${ }^{10}$ Se trata de esa misma noción aristotélica del "animal político" formulada por Parra en su entrevista con Benedetti, que le permitía sugerir que toda poesía era ineludiblemente política. Ahora bien, la organización de la antología desmiente esta idea tan amplia del término, porque en las doscientas páginas de Poesía política el gran peso de la selección corresponde a los años de mayor tensión política en Chile, mientras que escasean notoriamente los

\footnotetext{
${ }^{9}$ Véase www.leychile.cl.

${ }^{10}$ Enrique Lafourcade, "Nicanor Parra sin anti-parras", prólogo en Nicanor Parra, Poesía política (Santiago: Bruguera, 1983), 7-13.
} 
textos procedentes de los libros iniciales de Parra: no se incluye ninguno de Cancionero sin nombre (1937), La cueca larga (1958) ni Versos de salón (1962), y sólo uno de Poemas y antipoemas (1954).

Una breve descripción de las dieciséis secciones servirá como muestra:

1. "Nebulosa 1950". Lleva el subtítulo "Prácticamente inédito" e incluye un solo poema, "Mil novecientos treinta", publicado antes como el texto inicial del apartado "Otros poemas (1950-1968)" de Obra gruesa (1969).

2. "Poemas y antipoemas (1954)". Consiste exclusivamente en el poema "Soliloquio del Individuo".

3. "Canciones rusas (1967)". Se trata de tres poemas del libro homónimo, que fue escrito durante y después de una estancia de seis meses en Moscú durante 1963.

4. "La camisa de fuerza (1968)". En Obra gruesa, después de las "Canciones rusas", figuró el apartado "La camisa de fuerza. 19621968", del cual se incluyen cuatro textos.

5. "Otros poemas (1968)". Del extenso apartado "Otros poemas. 1950-1968" de Obra gruesa, se incluyen seis poemas, el primero de los cuales, "Manifiesto", fue publicado originalmente — como se ha señalado arriba- en 1963.

6. "Tres poemas (1968)". Se incluyen aquí los tres textos del último apartado de Obra gruesa.

7. "Poemas de emergencia (1972)". Se reproducen catorce textos del libro bilingüe Emergency Poems.

8. "Artefactos (1972)". Se incluyen veintinueve de los textos breves publicados como tarjetas postales en la caja de Artefactos, sin las ilustraciones del original.

9. "Sermones y prédicas del Cristo de Elqui (1977)". Consiste en tres poemas del libro homónimo.

10. "Nuevas sermones y prédicas del Cristo de Elqui (1979)". Incluye doce textos del libro homónimo.

11. "Poema y antipoema de Eduardo Frei" (1982). Consiste en los dos textos publicados en la plaquette de ese título.

12. "Cachureo". Cuatro textos inéditos.

13. "Chistes parra desorientar a la polié́a poesía". Incluye cuarenta $\mathrm{y}$ tres de los textos breves (sin las ilustraciones correspondientes) publi- 
cados en la caja Chistes parra desorientar a la policía poesía en 1983. En sección aparte, "+ Chistes", aparecen cinco inéditos.

14. "Ecopoemas". Consiste en treinta y siete textos, inéditos con la excepción de dos que formaron parte de Ecopoemas (1982).

15. "Guatapiques". Treinta y nueve breves textos, algunos ya publicados en la caja Chistes parra desorientar a la polieia poesía.

16. "Últimos sermones". Cinco textos inéditos que conforman una continuación de los dos tomos ya mencionados de Sermones y prédicas del Cristo de Elqui.

Una simple ojeada a estas secciones permite confirmar que no se trata, en términos generales, de una antología "política" en el sentido más amplio del zoon politikon designado por Lafourcade. En otro momento de su prólogo, éste veía lo político en la poesía de Parra en su "toma de conciencia real frente a diversas situaciones ocurridas en el mundo y en nuestro país", y lo cierto es que la mayoría de los poemas se fechan en la época de crispación ideológica vivida durante los gobiernos de Eduardo Frei Montalva y Salvador Allende, y luego durante la dictadura de Pinochet, y son respuestas más o menos explícitas a la contingencia política.

Tal vez sea conveniente recordar, aquí, que el poeta español Guillermo Carnero definía como política la poesía que enfoca lo social "desde una ideología concreta, o para fines prácticos coyunturales", y actúa en "una coyuntura histórica determinada, en la que exista fe, programa o enemigo". En ese sentido, deslindaba el concepto de "poesía política" de los de "poesía humana" - la que se centra en "cuestiones íntimas personales (amorosas, religiosas, vitales en general)"- y de "poesía social", a la que definía como una "poesía humana colectiva", que plantea "cuestiones derivadas necesariamente de la organización en colectividad de la vida humana" y que, además, "enfoca esas cuestiones desde la perspectiva del sujeto colectivo interpretado por el autor, o bien desde una individualidad que se define en lo que tiene de representativo de la colectividad". Como muestra de las fronteras movedizas entre poesía "humana", "social" y "política", Carnero ofrecía el siguiente ejemplo:

Un poeta nos escribe un poema lamentándose porque en su vida no hay amor; estaríamos ante un poema humano. Si lo continúa explicando que eso se debe a que en su país existen unas estruc- 
turas sociales y familiares fuertemente conservadoras, estamos ante un poema social. Y si prosigue pidiendo que ocurra una revolución que acabe con las clases dominantes y su ética, tenemos un poema político. ${ }^{11}$

Hacer hincapié en la poesía política de Parra, en 1983, permitía resaltar el papel del poeta no sólo como opositor en una coyuntura histórica determinada, que abarcaba tanto la Revolución Cubana y la Unidad Popular como el régimen pinochetista, sino también como disidente respecto de la poesía política de izquierda heredada de Neruda (una presencia más viva que nunca durante los años de la dictadura que fue, directa o indirectamente, responsable de la precipitación de su muerte) y acaparada por numerosos escritores chilenos, sobre todo en el exilio. El prólogo de Lafourcade se centra, precisamente, en las desavenencias políticas de Parra con la Revolución Cubana - "Le criticaron una taza de té con la señora Nixon. Fidel Castro lo envió al leprosario. Y, naturalmente, toda la horda de secuaces castristas acataron la decisión de este mandarín" - , surgidas a raíz de ese desafortunado incidente en la Casa Blanca en abril de 1970, y luego en los ataques a Parra por parte de los "mediocres escribas" en el exilio que se dedicaban a "impugnar y anatemizar con previsibles epítetos a los escritores que cometen el desacato revolucionario de vivir en su tierra, corriendo todos los riesgos y alzando la voz cada vez que es posible". En fin, con tono abiertamente ensalzador de Parra ("la primera voz lírica no sólo de Chile, sino del mundo hispánico"), Lafourcade celebraba el hecho de que "Nicanor, en su fuerte exilio interno, da la pelea. No desfilando y rezongando y zanganeando, como tanto exiliado político que pena y muere por las prebendas y privilegios de que disfrutara durante el allendismo". ${ }^{12}$

La inclusión en la antología de poemas alusivos a la Revolución Cubana y a la época de la Unidad Popular, junto a otros que criticaban la dictadura, así como nuevos textos que eran fruto de su recién adquirida militancia poético-ecológica, daba sustancia a esa denominación de "política" a las últimas secciones de la antología. Más problemática, sin duda, era la atribución de una intención política a las escasas muestras

${ }^{11}$ Guillermo Carnero, "Precedentes de la poesía social de la posguerra española en la anteguerra y guerra civil", Boletín de la Fundación Juan March 128 (julioagosto de 1983), 4-5.

${ }^{12}$ Citas en este párrafo: Lafourcade, "Parra sin anti-parras", 9-12. 
de su obra anterior. El crítico Ignacio Valente apuntaría a este desajuste al afirmar, en su reseña de la antología, que Poesía política "contiene excelentes poemas que no son políticos — como 'Defensa de Violeta Parra'-, otros que lo son en sentido amplio - batallas campales de robots y energúmenos, fantasmas ecológicos, crítica de la vida nacional-y muchos que son políticos en sentido propio y directo”. Eso sí, Valente logró iluminar el sentido de la antología con su establecimiento de un contraste entre la poesía política de Neruda - una poesía seria, de "contenido revolucionario bajo un lenguaje "tradicional", propensa a caer "en lo panfletario, en lo pedagógico, en la explicación y la apología" - y la de Parra, que "consigue la subversión más íntegra del lenguaje mismo, operando a través de ese elemento político por excelencia que es su ironía". ${ }^{13}$

\section{"SOLILOQUIO DEL INDIVIDUO": ¿POESÍA POLÍTICA?}

Lo que me interesa examinar, en las páginas siguientes, es la adscripción de "político" a los dos primeros poemas de la antología de Poesía política, ambos escritos en los años que Parra vivía en Oxford (1949-1951): "Mil novecientos treinta" y "Soliloquio del Individuo".

En el segundo de estos textos - uno de los poemas o antipoemas más célebres de Parra-, el intento de abarcar poéticamente la historia de la humanidad y articular una continuidad entre pasado, presente y futuro invitaba a un diálogo con dos de las más prestigiosas muestras de poesía política de la época: por un lado, el conjunto de obras publicadas por Neruda a partir de España en el corazón (1937) y que llegaría a su culminación con el imponente Canto general, publicado en 1950 cuando Parra estaba ya viviendo en Oxford; por otro lado, el poema "Spain", de W. H. Auden, publicado por primera vez en 1937.

En Canto general, desde una perspectiva orgullosamente marxista, Neruda partía del pasado, de las tierras y los hombres originarios de "Amor América (1400)" y del "Macchu Picchu" incaico, deslumbrante en su majestuosidad pero construido sobre sangre de esclavos, para trazar la historia continental desde la llegada de los españoles hasta el presente como una lucha secular entre las fuerzas de opresión (los conquistadores, los verdugos, los tiranos) y las de liberación (los liber-

${ }^{13}$ Ignacio Valente, "Poesía política”, El Mercurio, 18 de diciembre de 1983. 
tadores, los revolucionarios, los comunistas), en la que el "árbol del pueblo", a pesar de las derrotas, nunca dejó y nunca dejaría de florecer en el camino hacia un futuro sin injusticias, ya anticipado en el presente en la Unión Soviética.

Por otra parte, era inevitable que el descubrimiento de Auden, el más prestigioso de los poetas británicos de los años treinta, impactara profundamente a Parra. Era un poeta frío y analítico (como Parra), que experimentaba con la recuperación de la poesía popular de raíz oral de las baladas (como Parra con las coplas y las cuecas) y que incorporaba en su poesía (al igual que Parra) la ironía y el humor. Este impacto de Auden se notaría con claridad, años más tarde, en el curioso "Discurso de bienvenida en honor de Pablo Neruda", que leyó Parra en ocasión del nombramiento de Neruda como Miembro Académico de la Facultad de Filosofía y Educación de la Universidad de Chile, en 1962. Al final de ese discurso, sin mencionar siquiera el nombre de Auden, leyó una traducción (¿propia?) de varias estrofas del poema "Spain", como muestra - afirmaba - de que el hombre contemporáneo debía luchar por superar la alienación de la vida moderna mediante la aceptación de sus "deberes". 14

El poema de Auden se articula dialécticamente entre el ayer del ser humano a lo largo de su historia, el hoy de la guerra de España y el futuro de una sociedad en la que ha triunfado la revolución. "Yesterday all the past": desde la primera estrofa, el poema elabora una enumeración, puntuada por la insistente anáfora de "ayer", de una serie de hitos en la evolución de la humanidad. Curiosamente, Parra excluyó esa estrofa inicial, tan explicativa en su resumen — "Ayer todo el pasado"_-, y la exclusión me hace pensar que él mismo se encargaba de la traducción y prefería simplemente, ante la dificultad de traducir términos como "counting-frame", "cromlech" y "shadow-reckoning", omitir esos versos.

"Spain" avanza a través de la evolución del ser humano mediante alusiones a la adivinación del futuro, la invención de la rueda y el reloj, la domesticación del caballo, las fortalezas medievales, la Inquisición y los aquelarres, y luego, a partir de la cuarta estrofa, la llegada de la Revolución Industrial y los descubrimientos de Darwin: “Ayer la inten-

${ }^{14}$ Nicanor Parra, "Discurso de bienvenida en honor de Pablo Neruda", en Obras completas \& algo + / Vol. I (Barcelona: Galaxia Gutenberg - Círculo de Lectores, 2006), 736-738. 
sificación de dínamos y de turbinas, / de líneas férreas en los desiertos coloniales; / ayer, la clásica conferencia / acerca del origen del hombre". En este extraño, a veces zigzagueante collage de hechos o hitos de la historia humana, el poeta comenzaba a añadir, desde la tercera estrofa (en la versión leída por Parra; la cuarta en el poema original de Auden), la coda "pero hoy, la lucha": "but to-day the struggle". "Spain", en su primera versión de 1937, dedicó seis estrofas al "ayer", trece al "hoy", cuatro al "mañana" y luego tres a un epílogo. Parra, en su traducción abreviada de esa versión, incluiría cinco dedicados al "ayer", parte de una sola estrofa al "hoy", cuatro estrofas al "mañana" y eliminó el epílogo. Los tres versos dedicados al presente remitían infaliblemente a los lectores chilenos - y al público de autoridades que oía el discurso en 1962 - a la poesía sobre la guerra de España del propio Neruda:

Madrid es el corazón. Nuestros momentos de ternura florecen ahí en forma de ambulancias y de sacos de arena.

Nuestras horas de amistad ingresan al ejército del pueblo. ${ }^{15}$

Neruda: España en el corazón; Auden: Madrid es el corazón. Para ambos, la guerra de España fue una especie de parteaguas en la historia, la toma de conciencia de la necesidad de luchar contra el fascismo.

"Mañana quizás el futuro" ("Tomorrow, perhaps, the future"), escribió Auden, en su paso del presente de la guerra civil a la sociedad que surgiría (quizás) del triunfo de la lucha, en un futuro puntuado esta vez con la anáfora "mañana". Llama la atención lo poco que el mundo postrevolucionario pintado por el inglés tenía que ver con la Unión Soviética que Neruda celebraría, en 1950, como modelo para el futuro de la humanidad, y lo cierto es que desde la primera publicación de "Spain" los críticos atacaban por ello al poeta inglés, condenando la falta de detalles sobre la organización igualitaria y el funcionamiento de la sociedad, y la insistencia, en cambio, en elementos notoriamente pequeñoburgueses de ese mundo futuro ("el redescubrimiento del amor romántico; / las fotografías del cuervo", "el intercambio de ideas acerca de la crianza de perros finos", "los paseos por el lago", "las carreras de bicicletas / por los suburbios en atardeceres de verano").

${ }^{15}$ Parra, "Discurso de bienvenida". 
Al ensayar, en "Soliloquio del Individuo", una visión sobre la evolución del ser humano, Parra establecía un diálogo implícito con la visión de la historia como progreso presente tanto en Canto general de Neruda como en el poema "Spain". Al igual que en el texto de Auden, hay una enumeración de diversos hitos de la historia de la humanidad: el descubrimiento del fuego, la grabación de figuras en una roca, la producción de "ciencias, verdades inmutables", la invención del fonógrafo y la máquina de coser, etcétera. No obstante, en "Soliloquio" estos hitos pertenecen a la búsqueda no de un colectivo, sino de un "Individuo" transhistórico — escrito así, con "I" mayúscula - que descubre e inventa siempre a solas, y que cuando encuentra (¡asombrado!) a otros que también descubren, también inventan, rehúye el contacto, responde a sus preguntas con evasivas, rechazando implícitamente la comunicación y la colaboración que ofrecen, antes de regresar a sus búsquedas solitarias:

Bajé a un valle regado por un río,

Allí encontré lo que necesitaba,

Encontré un pueblo salvaje,

Una tribu,

Yo soy el Individuo.

Vi que allí se hacían algunas cosas,

Figuras grababan en las rocas,

Hacían fuego, ¡también hacían fuego!

Yo soy el Individuo.

Me preguntaron que de dónde venía.

Contesté que sí, que no tenía planes determinados,

Contesté que no, que de ahí en adelante.

Bien.

Tomé entonces un trozo de piedra que encontré en un río

Y empecé a trabajar con ella,

Empecé a pulirla,

De ella hice una parte de mi propia vida. ${ }^{16}$

Auden pintaba el mundo ocioso y feliz que estaba destinado a suceder en el futuro, siempre que se ganara la guerra de España; Neruda,

16 Nicanor Parra, "Soliloquio del Individuo", de Poemas y antipoemas, en Obras completas I, 61 . 
por su parte, auguraba una sociedad próspera, sin clases ni exclusiones, a raíz de su encarnación presente en los países comunistas de Europa y Asia (Canto general, Las uvas y el viento), y se dirigía al "hombre sencillo" de las Odas elementales (publicadas pocos meses después de Poemas y antipoemas, en 1954) para consolar y animarlo con sus conocimientos proféticos - dones de la escritura - sobre el triunfo futuro de la revolución: "ven, / no sufras, / ven conmigo, / porque aunque no lo sepas, / eso yo sí lo sé; / yo sé hacia dónde vamos, / y es ésta la palabra: / no sufras / porque ganaremos, / ganaremos nosotros, / los más sencillos, / ganaremos, / aunque tú no lo creas, / ganaremos". ${ }^{17}$

Para el Auden de "Spain", para Neruda, la historia tenía sentido. En el "Soliloquio" de Parra, en cambio, la acumulación de conocimientos, medios de expresión y artefactos tecnológicos surge, de manera aleatoria, como el fruto de una fuerza vital ciega, de una insatisfacción permanente ("pero yo debía seguir adelante") que lleva al Individuo a desplazarse sin parar, obsesionado siempre por la adquisición de nuevas experiencias, nuevos productos, hasta el momento de revelación de los últimos versos:

Miré por una cerradura,

Sí, miré, qué digo, miré,

Para salir de la duda miré,

Detrás de unas cortinas,

Yo soy el Individuo.

Bien.

Mejor es tal vez que vuelva a ese valle,

A esa roca que me sirvió de hogar,

Y empiece a grabar de nuevo,

De atrás para adelante grabar

El mundo al revés.

Pero no: la vida no tiene sentido. ${ }^{18}$

Por un instante, el Individuo se detiene y abre los ojos para satisfacer su "duda" y averiguar el sentido de sus andanzas, mirando por la

${ }^{17}$ Pablo Neruda, "Oda al hombre sencillo", en Odas elementales (Santiago de Chile: Pehuén Editores, 2005), 109.

18 Parra, "Soliloquio", 64. 
cerradura. El ritmo obstruido - “Sí, miré, qué digo, miré" - reproduce la conturbación que experimenta al conocer la verdad. No se nos comunica, a los lectores, esa revelación, pero vemos que es lo suficientemente desoladora como para que el Individuo contemple la posibilidad de volver atrás, desandar lo andado. "Pero no: la vida no tiene sentido": la historia no es progreso, no habrá futuro feliz sin clases ni injusticias, pero tampoco hay vuelta atrás. Frente al optimismo histórico de Canto general, y muy posiblemente en el mismo año en que ese libro se publicara, Parra fijó en este poema, que cerraría sus Poemas y antipoemas, una visión netamente pesimista de la historia.

¿"Soliloquio del Individuo" es un poema político? ¿Muestra, como quería Lafourcade, una "toma de conciencia real" ante "situaciones ocurridas en el mundo y en nuestro país"? ¿Actúa, como pedía Carnero, en "una coyuntura histórica determinada, en la que exista fe, programa o enemigo", con una "ideología concreta" y con "fines prácticos coyunturales"? La coyuntura era la Guerra Fría recién establecida, que Parra había vivido en Chile, en 1948, con la proscripción del Partido Comunista, la persecución de sus militantes y la larga clandestinidad de Neruda, y que vivía ahora en la empobrecida Inglaterra de la postguerra, donde George Orwell acababa de publicar su visión apocalíptica del totalitarismo en 1984, donde The God that Failed reunía escalofriantes relatos autobiográficos sobre su "fe" comunista de intelectuales que se habían alejado del Partido, y donde el Uncle Joe de cinco años antes era ahora el carnicero del Gulag, la gran amenaza a los valores democráticos de Occidente y a la libertad individual. Para el Parra del "Soliloquio", la evolución del mundo era un producto de la pulsión vital de individuos permanentemente insatisfechos, mientras que la colectividad de la "tribu" — desde la perspectiva de la evolución - era sedentaria, anecdótica, infecunda. La revelación final del sinsentido del mundo, del vacío existente por debajo y detrás de las apariencias de "progreso", podría haber llevado a Parra a expresar, como desenlace triunfal de su libro, una apuesta por otra forma de ser, por una renuncia al individualismo, por un optimismo histórico fundamentado en la lucha de clases. No lo hizo, y en ese sentido su poema es político: en su rechazo simultáneo a la ideología liberal y a la ideología marxista que en ese mismo año de 1950 articularía el libro de poesía política por excelencia del siglo XX: Canto general. 


\section{¿POR QUÉ "MIL NOVECIENTOS TREINTA"?}

El título de la primera sección de Poesía política, "Nebulosa 1950", vincula su único poema, "Mil novecientos treinta", a la niebla que seguiría atormentando la ciudad de Oxford hasta el Clean Air Act de 1956, pero también al estado de incertidumbre y confusión de la época en que Parra vivía en Inglaterra, y que se palpaba en esos versos finales que hemos visto de "Soliloquio del Individuo". "Mil novecientos treinta" era un poema que gustaba, evidentemente, a Parra, o le gustaría por lo menos en años posteriores cuando inició con él "Otros poemas" de Obra gruesa y la antología Poesía política. ¿Por qué decidió no incorporarlo a Poemas y antipoemas? Debe de haber pensado, creo yo, que su extensión, su visión del mundo y su interés en la historia se solapaban con el papel que tenía, al final de ese libro, el "Soliloquio".

En un ensayo de 2012, señalé el vínculo entre "Mil novecientos treinta" y los inicios de "A Berlin Diary (Autumn 1930)", el capítulo inaugural de la novela Goodbye to Berlin, publicada en 1939 por Christopher Isherwood, el gran amigo y compañero de escritura de Auden ${ }^{19}$. El segundo párrafo del libro de Isherwood es el fragmento más citado de toda su obra:

I am a camera with its shutter open, quite passive, recording, not thinking. Recording the man shaving at the window opposite and the woman in the kimono washing her hair. Some day, all this will have to be developed, carefully printed, fixed.

(Soy una cámara con el obturador abierto, completamente pasiva, no pienso: registro. Registro al hombre que se afeita en la ventana opuesta, y a la mujer en kimono que se lava el pelo. Algún día habrá que revelar, imprimir meticulosamente y fijar todo esto). ${ }^{20}$

El guiño de Parra a Isherwood resulta evidente desde el inicio del poema y funciona a varios niveles:

Mil novecientos treinta. Aquí empieza una época

Con el incendio del dirigible R101 que se precipita a tierra

${ }^{19}$ Niall Binns, Nicanor Parra o el arte de la demolición (Valparaíso: Editorial de la Universidad de Valparaíso, 2014), 236-237.

${ }^{20}$ Christopher Isherwood, Adiós a Berlín (Barcelona: Argos - Vergara, 1981), 12. 
Envuelto en negras ráfagas de humo

Y en llamas que se ven desde el otro lado del Canal

Yo no ofrezco nada especial, yo no formulo hipótesis

Yo sólo soy una cámara fotográfica que se pasea por el desierto

Soy una alfombra que vuela

Un registro de fechas y de hechos dispersos

Una máquina que produce tantos o cuantos botones por minuto. ${ }^{21}$

La identificación del yo con una cámara crea un diálogo inmediato entre ambos textos ("I am a camera", "Yo sólo soy una cámara fotográfica") y permite que se relacionen el título y las primeras palabras del poema con la fecha de ese "diario de Berlín” de 1930 de Isherwood. “Aquí empieza una época”, cuenta el hablante de Parra. Pues eso fue, precisamente, lo que pretendía Isherwood en su novela: registrar con rigurosa objetividad fotográfica (algo que es, lo sabemos, imposible) los inicios del nazismo. En el primer capítulo del libro del inglés surgen los primeros disturbios nazis en la ciudad y se nos presenta a Fräulein Mayr, una "ardiente nazi" que vive en la misma casa de huéspedes del narrador, y que atormenta a la mujer judía del piso de abajo enviando una carta anónima, cargada de calumnias, a su pretendiente y escuchando con júbilo como éste le propina una paliza. ${ }^{22}$ El penúltimo capítulo, "Los Landauer", se inicia con una manifestación nazi de octubre de 1930 , en la cual hubo ataques a ciudadanos judíos y se rompieron los cristales de "todos los comercios judíos". El narrador lo recuerda como su "primer contacto con la política en Berlín", y anota la reacción entusiasmada de Fräulein Mayr:

¡A ver si escarmientan! — comentó- . La ciudad está harta de los judíos. Das una patada a una piedra y debajo hay un par de ellos. ¡Están envenenando hasta el agua que bebemos! Nos están estrangulando, robando, chupando la sangre. Mira todos esos grandes almacenes: Wertheim, K.D.W., Landauer. ¿De quién son? ¡De asquerosos ladrones judíos! ${ }^{23}$

${ }^{21}$ Nicanor Parra, "Mil novecientos treinta", de Otros poemas (1950-1968), en Obras completas I, 205.

${ }^{22}$ Isherwood, Adiós a Berlín, 20-21.

${ }^{23}$ Ibídem, 154. 
En agosto de 1931, en una fiesta organizada por Bernhard Landauer, el narrador piensa en una amiga judía que ha huido de Alemania y reflexiona que "por mucho que pudiera postergarse la decisión, todo aquel pueblo estaba en última instancia condenado. Aquella noche era el ensayo general de un desastre. Como la última noche de una época". ${ }^{24}$ La nueva época se inaugura, durante los meses siguientes, con anónimas amenazas de muerte a Bernhard y a todos los "asquerosos judíos", ${ }^{25}$ y en el último capítulo del libro, "Un diario de Berlín (Invierno de 1932-33)", Hitler ya está instalado en el poder y se ha emprendido una persecución sistemática contra la población judía de la ciudad.

A Isherwood - como a Parra, después - le interesaba, a partir de su propia experiencia en Alemania, ese cambio de época surgido de algún modo a comienzos de la década de los treinta. La fecha de publicación de su novela, 1939 (aunque fue terminada, en realidad, años antes), coincidía además con el comienzo de la guerra mundial, lo cual aumentaba la invitación a leerla como un estudio de los prolegómenos del conflicto en la decadencia de la República de Weimar (depresión económica, pobreza, inflación, crispación ideológica) y los primeros ataques antisemitas de los nazis.

Parra, por su parte, retomaba la fecha de 1930 y la imagen de la cámara para situarse en los prolegómenos no de la Guerra Mundial, sino de la Guerra Fría, cuyos comienzos estaba viviendo en Inglaterra. Ahora bien, el narrador de Adiós a Berlín —que se llama precisamente Christopher Isherwood o, según la pronunciación de la dueña de la casa de huéspedes, Fräulein Schroeder, "Herr Issyvoo"- se anuncia como un testigo (objetivo, eso sí) del mundo berlinés que relata; el yo de Parra, en cambio, emprende un viaje por el mundo: es no sólo una cámara fotográfica, sino también "una alfombra que vuela", registrando a su paso todo tipo de hechos y fechas.

En un primer momento, el yo-cámara o yo-alfombra se sitúa en Inglaterra, observando las llamas que surgen, desde el otro lado del Canal de la Mancha, del R101. Destinado a ser uno de dos dirigibles que comunicarían al Reino Unido con Estados Unidos y las colonias, iba a competir por la supremacía del cielo con el Graf Zeppelin alemán. Coreado por miles de británicos entusiasmados por la hazaña, el R101 —de

\footnotetext{
${ }^{24}$ Isherwood, Adiós a Berlín, 191.

${ }^{25}$ Ibídem, 193.
} 
tamaño imponente, casi 240 metros de longitud - despegó en su viaje inaugural el 4 de octubre de 1930, llevando a bordo doce pasajeros y una tripulación de cuarenta y dos. Al cruzar el Canal, en condiciones climáticas nefastas, el dirigible fue incapaz de alcanzar la altura adecuada y terminó estrellándose contra un bosque a las afueras de la ciudad francesa de Beauvais. Este desastre llevó a los británicos a abandonar su proyecto de fabricar dirigibles y a dejar de equipararse con el nivel de la tecnología aeronáutica alemana. "Aquí empieza una época", dice el yo-cámara de Parra: comenzaba con la crisis del Reino Unido, de las democracias liberales y con la ventaja concedida a Alemania.

Las estrofas siguientes se fijan en dos expediciones europeas malogradas, mostrándolas tal vez como anticipos simbólicos de la decadencia del continente. En primer lugar, se habla del rescate de los cadáveres del aventurero sueco Salomon Augusto Andrée, que en 1897 murió mientras intentaba alcanzar el Polo Norte en globo. El 5 de agosto de 1930, se encontraron en el archipiélago de los Svalbard, en Noruega, los cuerpos de Andrée y sus dos compañeros junto con sus mapas, diarios y negativos fotográficos. La tercera estrofa, por su parte, se centra en la expedición internacional, dirigida en mayo de 1930 por el doctor Günter Oskar Dyhrenfurth y su mujer, Hettie, que fracasó en su intento de escalar el Kangchenjunga, de 8.586 metros de altura.

A lo largo de estas estrofas, el yo-cámara (o yo-alfombra) no deja de dar fe de sí mismo: "primero indico los cadáveres", "señalo el lugar preciso", "he ahí el trineo", "me remonto a uno de los picos", "miro con escepticismo", "veo cómo el viento los rechaza", "veo a algunos de ellos resbalar y caer al abismo", "a otros veo luchar entre sí". La cuarta estrofa se dirige enteramente a esta autorreflexión del yo, insistiendo de nuevo en la imparcialidad y ecuanimidad que pretende encarnar:

Pero no todo lo que veo se reduce a fuerzas expedicionarias:

Yo soy un museo rodante

Una enciclopedia que se abre paso a través de las olas

Registro todos y cada uno de los actos humanos.

Basta que algo suceda en algún punto del globo

Para que una parte de mí mismo se ponga en marcha

En eso consiste mi oficio

Concedo la misma atención a un crimen que a un acto de piedad

Vibro de la misma manera frente a un paisaje idílico 
Que ante los rayos espasmódicos de una tempestad eléctrica

Yo no disminuyo ni exalto nada.

Me limito a narrar lo que veo. ${ }^{26}$

Este desplazamiento de la pretendida objetividad fotográfica a una especie de omnisciencia y omnipresencia más propia del Neruda de Canto general resulta, sin duda, curioso. Se trata de una tendencia expansiva del yo poético que existe en este poema y en "Soliloquio del Individuo" (la propuesta de abarcar la evolución de la humanidad), pero en muy pocos lugares en el resto de la obra de Parra, que suele buscar más bien una horizontalidad en su perspectiva, poniéndose al nivel del hombre "común y corriente" en las limitaciones de su mirada y en su lenguaje. De todos modos, en los versos citados arriba me parece interesante subrayar que estamos lejos del impulso profético que engrandece al yo poético nerudiano. Llama la atención, en este sentido, que el yo parriano afirma estar "narrando", lo que vuelve a vincular su estrategia a la de Isherwood, pero también a los párrafos autorreflexivos que envió Parra en 1948, como prefacio a sus primeros antipoemas, a la antología 13 poetas chilenos, de Hugo Zambelli, y en los que se comparaba en su mirada científica a un novelista: "Me siento más cerca del hombre de ciencia que es el novelista que del poeta en su acepción restringida. (...) El lenguaje periodístico de un Dostoievski, de un Kafka o de un Sartre, cuadran mejor con mi temperamento que las acrobacias verbales de un Góngora o de un 'modernista' tomado al azar". ${ }^{27}$

"No todo lo que veo se reduce a fuerzas expedicionarias", afirma el yo de "Mil novecientos treinta", y en la quinta y la sexta estrofas enumera una serie de sucesos políticos de ese año: las manifestaciones contra la Ley de la Sal dirigidas en la India por Mahatma Gandhi, entre marzo y abril de 1930; las condenas, por parte del Vaticano, a las "persecuciones religiosas de la Rusia soviética"; el regreso a Rumania del "príncipe Carol", el 6 de junio de 1930, para coronarse rey y adueñarse del país; la ejecución de "terroristas croatas y eslovenos" durante la dictadura del rey Aleksandar de Croacia; la permanencia en la presidencia de Portugal del general Óscar Carmona, que preparaba el terreno para la dictadura de António de Oliveira Salazar; el exterminio de los

\footnotetext{
${ }^{26}$ Parra, "Mil novecientos treinta", 205.

${ }^{27}$ Parra, Obras completas I, 691.
} 
"kulaks" — sobre todo en Ucrania—, sancionado por el decreto de 30 de enero de 1930, que llevó a la muerte a millones de campesinos en aras de la colectivización agraria de la Unión Soviética; la Guerra de las Grandes Planicies, de 1930, que formó parte de las luchas intestinas del Kuomintang (es decir, el Partido Nacionalista Chino) y terminó con la victoria del general Chiang Kai-Shek.

"Esto fue y esto es lo que fue el año mil novecientos treinta", comienza la última estrofa del poema de Parra. Esto fue y esto es: las consecuencias de ese pasado seguían a la vista en 1950, con la confirmación de la pérdida de peso internacional del Reino Unido y con el establecimiento de la Guerra Fría. La Marcha de la Sal fue un primer hito en el camino hacia la independencia de la India, que se consiguió por fin en 1947, aunque la nueva constitución no entrara en vigor hasta el 26 de enero de 1950, cuando Parra estaba ya en Oxford. En 1950, el general Carmona seguía ejerciendo de presidente en Portugal, bajo la dictadura de Salazar. Las turbulencias en los Balcanes de 1930 habían desembocado en la instalación de la República Popular de Rumania, dentro del bloque comunista de la Guerra Fría, y en la incorporación de Croacia y Eslovenia a la República Federativa Popular de Yugoslavia, bajo el mando del mariscal Tito. El general Chiang, asediado por las fuerzas de Mao en la ciudad de Chengdu, huyó a Taiwán en diciembre de 1949, y asumió en Taipéi la presidencia de la República de China el 1 de marzo de 1950. Por último, las persecuciones religiosas y la liquidación de los kulaks constituían, para los países democráticos de Occidente, pruebas irrefutables de la barbarie de Stalin y, por lo tanto, de la falsedad de su supuesta superioridad moral.

Así, 1930 y 1950 se juntan bajo la mirada de Parra — que era capaz de regresar veinte años en el tiempo-, buscando las semillas no sólo del crecimiento del nazismo y la Segunda Guerra Mundial, sino de la Guerra Fría. Winston Churchill, en 1948, tituló el primer tomo de su monumental historia sobre la Guerra Mundial The Gathering Storm ("Cómo se fraguó la tormenta"). La Guerra Mundial fue - opinabauna guerra "innecesaria", provocada por la estupidez del Tratado de Versalles, que engendró el militarismo alemán y agravó la crisis económica desencadenada en 1929. Pero, con la victoria de 1945, la tormenta no amainó: 
Hemos emergido, por fin, de un escenario de ruina material y caos moral superior a cualquier otro que haya ensombrecido la imaginación en siglos anteriores. No obstante, después de todo lo que hemos sufrido y conseguido, estamos aún enfrentados a problemas y peligros no menores, sino infinitamente más formidables que los que con tanta dificultad hemos logrado sortear. ${ }^{28}$

En esos problemas y en esos peligros parecería querer instalarnos Parra, pero habría que terminar estas páginas relacionando "Mil novecientos treinta", una vez más, con Adiós a Berlín, de Isherwood. Éste, en una "nota preliminar" fechada por el autor en septiembre de 1935, reflexionó así sobre el narrador de su novela: "A pesar de haber prestado mi propio nombre al narrador de esta historia, el lector no debe suponer que estas páginas son simplemente autobiográficas ni que sus personajes son difamadores y exactos retratos de personas reales. 'Christopher Isherwood' no pasa de ser el cómodo muñeco del ventrílocuo". ${ }^{29}$ El novelista Isherwood es el ventrílocuo; su narrador, bautizado Isherwood también, no es más que un muñeco. Hablar en primera persona, equiparar textualmente narrador y autor, no significa caer en la subjetividad. Parra estaba interesado en esta distinción. El yo poético que habla en los antipoemas invita al lector a una identificación con el autor, pero en la caracterización confusa, a menudo delirante, de ese yo se abre a la vez una insistente grieta que impide la identificación.

Conviene recordar, en este sentido, el fragmento de una carta, fechada en noviembre de 1949, que envió Parra desde Oxford a su amigo Tomás Lago, en la que insistía en que "la poesía egocéntrica de nuestros antepasados en que ellos tratan de demostrar al lector cuán estimable es el ser humano, cuán inteligentes y sensibles son ellos, cuán dignos de admiración son los objetos de este mundo, debe ceder el paso a una poesía más objetiva de simple descripción de la naturaleza del hombre". ${ }^{30}$ En una imagen no tan lejana a la del yo-cámara, pero más científica que periodística en sus connotaciones, afirmaba que el poeta "debe ser un ojo que mira a través de un microscopio en cuyo extremo

28 Winston Churchill, The Second World War. The Gathering Storm (Cambridge, MA: The Riverside Press, 1948), 17.

${ }^{29}$ Isherwood, Adiós a Berlín, 7.

${ }^{30}$ Nicanor Parra, "Carta a Tomás Lago", en Obras completas I, 1024. 
pulula una fauna microbiana". ${ }^{31}$ El personaje Christopher Isherwood, con su soledad y su torpeza social, es fauna microbiana; el yo que habla en los antipoemas es fauna microbiana. ¿Lo es, también, el yo-cámara en su alfombra mágica, mientras vuela por el mundo y atrás en el tiempo, hasta 1930, "año en que yo me sitúo y soy en cierto modo situado"? 1930: la gran depresión, el despertar del nazismo, las semillas iniciales de la Guerra Mundial y de la Guerra Fría.

Los últimos versos de "Mil novecientos treinta" emprenden un sorprendente cambio de dirección, llevando al yo por primera vez a tierras americanas:

Esto fue y esto es lo que fue el año mil novecientos treinta

Así fueron exterminados los kulaks de la Siberia

De este modo el general Chang cruzó el río Amarillo y se apoderó de Pekín.

De ésta y no de otra manera se cumplen las predicciones de los astrólogos

Al ritmo de la máquina de coser de mi pobre madre viuda

$\mathrm{Y}$ al ritmo de la lluvia, al ritmo de mis propios pies descalzos

$\mathrm{Y}$ de mis hermanos que se rascan y hablan en sueños. ${ }^{32}$

¿Qué significa este giro desde algunos de los grandes acontecimientos "históricos" de 1930 hacia el ámbito familiar? El adjetivo "pobre", con el que el yo-cámara —o hasta ahora cámara - se refiere a su madre viuda, revienta la objetividad tan calculadamente neutra de antes - "concedo la misma atención a un crimen que a un acto de piedad"; "yo no disminuyo ni exalto nada"; "yo dejo hacer, dejo pasar / dejo que se les asesine tranquilamente"- y nos instala en un testimonio del mundo subjetivo de la pobreza, del frío, de las pulgas y los pies descalzos. ¿Cómo leer, cómo interpretar este final del poema? ¿Está diciendo que todas las pretensiones de objetividad son falsas, que la objetividad y la aspiración a la universalidad son imposibles, que la subjetividad del yo sufriente siempre terminará por asomar en el poema? En cierta medida debe de ser así, a no ser que el yo se estuviera ofreciendo a sí mismo, también, como "fauna microbiana", como objeto de estudio, al igual que ese narrador Christopher Isherwood de Adiós a Berlín. Se

\footnotetext{
${ }^{31}$ Parra, "Carta", 1024.

32 Parra, "Mil novecientos treinta", 205.
} 
trata, en cualquier caso, de un cuestionamiento de la imagen del yocámara que ha dominado a lo largo del poema, un reconocimiento quizá que esa objetividad testimonial a la que aspiraban la fotografía y la literatura, sobre todo en los años treinta, era mentira. ¿Equipara el poema la importancia "histórica" de 1930, un año que sembró lo que aún se cosechaba dos décadas más tarde, con la importancia "intrahistórica" que tenía 1930 para el autor Nicanor Parra, con la muerte de su padre y su decisión de dejar Chillán, instalarse en Santiago, trabajar para enviar remesas a su familia, estudiar para ser científico, convertirse en poeta, y en 1950 cosechar los frutos de ese dolor y ese impulso de dos décadas antes, mediante su beca como estudiante doctoral en la Universidad de Oxford y su escritura de los textos que formarían parte, poco después, de Poemas y antipoemas? Pero esa "intrahistoria" remite, además, a la idea tan prevalente en las últimas décadas - y que se palpaba a la vez en la sección central de "La tierra se llama Juan", de Canto generalsegún la cual la historia pertenece, también, a los que nunca tuvieron voz. Quizá no sea casualidad que la última parada sea, precisamente, la primera visita del yo-alfombra a América, como si el continente americano $-\mathrm{y}$ sobre todo, por supuesto, Latinoamérica, encarnada en la familia del Parra que nos habla en el poema - hubiese sido olvidado siempre por el eurocentrismo de la gran Historia.

\section{POLÍTICA Y ANTIPOESÍA EN LOS AÑOS CINCUENTA}

La inclusión en Poesía política de estos dos textos, "Soliloquio del Individuo" y "Mil novecientos treinta", como los únicos representantes de la primera época de Parra se debe a su indagación, desde tierras inglesas, de la compleja encrucijada de la Guerra Fría y, sobre todo, a su rechazo al progresismo optimista encarnado por el Neruda de Canto general. Sugerí antes que la decisión de excluir "Mil novecientos treinta" de Poemas y antipoemas podría deberse a su solapamiento con el mundo del "Soliloquio". Más probable me parece, ahora, pensar que las alusiones no precisamente positivas a la Unión Soviética resultarían demasiado complicadas en un libro publicado en Chile, en 1954, con el beneplácito de Neruda presente hasta en la cubierta de la primera edición ("Esta poesía es una delicia de oro matutino o un fruto consumado en las tinieblas", etcétera). Resucitar las persecuciones religiosas 
de Stalin y su masacre de los kulaks habría descalificado de antemano el libro frente a un número importante de escritores, críticos y lectores chilenos que veían la Guerra Fría desde otro ángulo, tras sufrir, a veces en su propia carne, la proscripción del Partido Comunista y la persecución de sus militantes.

\section{OBRAS CITADAS}

Auden, W. H. Another Time. Londres: Faber \& Faber, 1996.

Benedetti, Mario. "Nicanor Parra o el artefacto con laureles". En Los poetas comunicantes. Montevideo: Marcha, 1972, 41-63.

Carnero, Guillermo. "Precedentes de la poesía social de la posguerra española en la anteguerra y guerra civil”. Boletín de la Fundación Juan March 128 (julioagosto de 1983): 3-20.

Churchill, Winston S. The Second World War. The Gathering Storm. Cambridge. MA: The Riverside Press, 1948.

Edwards, Jorge. Adiós, poeta... Barcelona: Tusquets, 1990.

Isherwood, Christopher. Adiós a Berlín. Barcelona: Argos-Vergara, 1981.

Lafourcade, Enrique. "Nicanor Parra sin anti-parras". En Nicanor Parra, Poesía politica. Santiago: Bruguera, 1983.

Neruda, Pablo. Odas elementales. Santiago: Pehuén Editores, 2005.

Parra, Nicanor. Poesía política. Prólogo de Enrique Lafourcade. Santiago de Chile: Bruguera, 1983.

- Obras completas \& algo + / Vol. I (1935-1972). Barcelona: Galaxia Gutenberg - Círculo de Lectores, 2006.

Valdivia Ortiz, Verónica, Rolando Álvarez \& Julio Pinto. Su revolución contra nuestra revolución. Izquierdas y derechas en el Chile de Pinochet (19731981). Santiago: LOM, 2006.

Valente, Ignacio. "Poesía política”. El Mercurio, 18 de diciembre de 1983.

Varios autores. "Carta abierta a Pablo Neruda". Casa de las Américas 38 (septiembre-octubre de 1966): 131-135. EP 